\title{
Deficiency of $\alpha$-I-antitrypsin influences systemic iron homeostasis
}

This article was published in the following Dove Press journal:

International Journal of COPD

21 January 2013

Number of times this article has been viewed

\author{
Andrew J Ghio' \\ Joleen M Soukup' \\ Judy H Richards' \\ Bernard M Fischer ${ }^{2}$ \\ Judith A Voynow ${ }^{2}$ \\ Donald E Schmechel ${ }^{3}$ \\ 'US Environmental Protection Agency, \\ Chapel Hill, NC, USA; ${ }^{2}$ Division \\ of Pediatric Pulmonary Medicine, \\ Department of Pediatrics, ${ }^{3}$ Joseph and \\ Kathleen Bryan Alzheimer Disease \\ Research Center, Department \\ of Medicine (Neurology), Duke \\ University Medical Center, Durham, \\ NC, USA
}

Correspondence:Andrew Ghio Campus Box 73I5, Human Studies Facility, US EPA, I 04 Mason Farm Road, Chapel Hill, NC 27599-73 I5, USA

Tel +l 9199660670

Fax + I 9199664767

Email ghio.andy@epa.gov
Abstract: There is evidence that proteases and antiproteases participate in the iron homeostasis of cells and living systems. We tested the postulate that $\alpha-1$ antitrypsin (A1AT) polymorphism and the consequent deficiency of this antiprotease in humans are associated with a systemic disruption in iron homeostasis. Archived plasma samples from Alpha-1 Foundation (30 MM, $30 \mathrm{MZ}$, and $30 \mathrm{ZZ}$ individuals) were analyzed for A1AT, ferritin, transferrin, and C-reactive protein (CRP). Plasma samples were also assayed for metals using inductively coupled plasma atomic emission spectroscopy (ICPAES). Plasma levels of A1AT in MZ and ZZ individuals were approximately $60 \%$ and $20 \%$ of those for MM individuals respectively. Plasma ferritin concentrations in those with the $\mathrm{ZZ}$ genotype were greater relative to those individuals with either MM or MZ genotype. Plasma transferrin for MM, MZ, and ZZ genotypes showed no significant differences. Linear regression analysis revealed a significant (negative) relationship between plasma concentrations of A1AT and ferritin while that between A1AT and transferrin levels was not significant. Plasma CRP concentrations were not significantly different between MM, MZ, and ZZ individuals. ICPAES measurement of metals confirmed elevated plasma concentrations of nonheme iron among ZZ individuals. Nonheme iron concentrations correlated (negatively) with levels of A1AT. A1AT deficiency is associated with evidence of a disruption in iron homeostasis with plasma ferritin and nonheme iron concentrations being elevated among those with the ZZ genotype.

Keywords: $\alpha$-1-antitrypsin deficiency, serpins, proteinase inhibitor proteins, ferritin, transferrin

\section{Introduction}

Alpha-1 antitrypsin (A1AT; also known as $\alpha-1$ proteinase inhibitor) is a serum glycoprotein which predominantly $(80 \%)$ originates from hepatocytes. ${ }^{1}$ A1AT inhibits a wide variety of proteases (eg, neutrophil elastase and proteinase-3) to contribute to a proteinase/antiproteinase balance. ${ }^{2}$ It is postulated that this acute phase protein participates in limiting host tissue injury by proteases at sites of inflammation; ${ }^{3}$ a proposed critical function is the prevention of lung injury associated with disruption of connective tissue by neutrophil elastase enzyme. ${ }^{1}$

A1AT deficiency is an autosomal recessive genetic disorder caused by its defective production leading to both decreased activity in body tissues and deposition of excessive abnormal protein in the liver. ${ }^{1,2}$ While $\mathrm{M}$ is the normal allele for A1AT, there are over 80 variant mutations of the gene. The $\mathrm{Z}$ allele results in a glutamate to lysine mutation at position 342 while the $\mathrm{S}$ allele produces a glutamate to valine mutation at position 264. In individuals with SS, MZ and SZ genotypes, blood levels 
of A1AT are reduced to between $40 \%$ and $60 \%$ of normal levels (ie, those observed among MM individuals). Among those who do not smoke, this A1AT concentration is almost always sufficient to protect the lungs from the effects of elastase. However, among individuals with the ZZ genotype, A1AT levels are usually less than $15 \%$ of normal and these deficient patients can develop lung disease at a young age. In addition, those with the $\mathrm{ZZ}$ genotype can develop liver disease; this is associated with impaired A1AT secretion and its consequent accumulation in this specific tissue. Therefore, A1AT deficient patients can present with lung disease (eg, panacinar emphysema [chronic obstructive pulmonary disease], pneumothorax, asthma, and bronchiectasis) and liver disease (eg, hepatitis, cirrhosis, and hepatocellular carcinoma). ${ }^{4}$ People of northern and western European ancestry are at the greatest risk for A1AT deficiency and its associated diseases ${ }^{5}$ 4\% carry the PiZ allele and between 1 in 1,500 and 1 in 2,500-3,000 are ZZ.

In addition to siderophores and ferrireductases, microbials employ proteases to mobilize host sources of iron to support their growth and replication. ${ }^{6}$ These proteases cleave irontransport and -storage proteins allowing utilization of the metal by the microbe. ${ }^{7,8}$ Corroborating a potential interaction between metal homeostasis and proteases, elevated iron concentrations impact expression of proteases and their activities. ${ }^{9-12}$ Animal and human investigation similarly suggests a participation of proteases in iron homeostasis. ${ }^{13-15}$ The intratracheal instillation of a single dose of neutrophil elastase in an animal model increased lung iron concentrations. Iron homeostasis is disrupted among cystic fibrosis patients in whom airway elastase content and activity is excessive; cystic fibrosis patients have elevated iron and ferritin concentrations in both the sputum and bronchoalveolar lavage.

A participation of proteases also suggests a potential involvement of anti-proteases in iron homeostasis. A1AT is the antiprotease in greatest concentration in humans. A participation of A1AT in the iron homeostasis of humans has been previously suggested with observations of deficient patients developing cirrhosis characterized by significant iron accumulation. ${ }^{16}$ An involvement of neutrophil elastase and A1AT in disrupting iron homeostasis of the lung was supported by investigation which demonstrated a proteolytic cleavage of both iron-transport and -storage proteins with subsequent increase in nonheme tissue iron concentrations. ${ }^{17}$ Finally, patients treated with antiproteases, and thus altering protease activity, can show evidence of disruptions in iron homeostasis. ${ }^{18}$ We further explored the relationship between A1AT and iron homeostasis in humans by testing the postulate that its deficiency is associated with a systemic disruption in iron homeostasis.

\section{Methods \\ Samples from MM, MZ, and ZZ individuals}

Archived plasma samples were kindly provided by the Alpha-1 Foundation (Miami, FL). These included 90 nonfasting plasma specimens from $30 \mathrm{MM}, 30 \mathrm{MZ}$, and $30 \mathrm{ZZ}$ individuals who had been screened as family members of a patient with A1AT deficiency. The health status of the donor was not known. Institutional Review Board exemption was granted from the University of North Carolina for analyses of these blood samples.

\section{Plasma assays}

Samples were analyzed for A1AT, ferritin, iron, transferrin, and C-reactive protein (CRP). A1AT and CRP concentrations were measured using immunoturbidimetric assay kits (DiaSorin Inc, Stillwater, MN). Ferritin was quantified by also using an immunoturbidimetric assay (Kamiya Biomedical Company, Seattle, WA). Transferrin concentrations were analyzed using an immunoprecipitin analysis (INCSTAR Corporation, Stillwater, MN). Assays were modified for use on the Konelab Arena 30 (ThermoLab Systems, Espoo, Finland).

\section{Measurements of metals in plasma}

Plasma samples were hydrolyzed at $70^{\circ} \mathrm{C}$ in $3 \mathrm{~N} \mathrm{HCl} / 10 \%$ trichloroacetic acid for 24 hours. After centrifugation, metals in the supernatant were measured using inductively coupled plasma optical emission spectroscopy (ICPOES; Model Optima 4300D; Perkin Elmer, Norwalk, CT).

\section{Statistics}

Data are expressed as mean values \pm standard error unless otherwise specified. Differences between groups were compared using one-way analysis of variance. The post-hoc test employed was Duncan's Multiple Range test. General linear regression modeling was used in delineating a relationship between two continuous variables. Significance was assumed at $P<0.05$.

\section{Results}

Demographics of healthy individuals providing archived plasma samples are listed (Table 1). There were differences in the gender distributions between the MM, MZ, and $\mathrm{ZZ}$ cohorts and subsequently results were provided for males and females. Disparities in age and ethnicity between the cohorts were not significant. 
Table I Demographics of healthy individuals providing plasma samples

\begin{tabular}{llll}
\hline & MM & MZ & ZZ \\
\hline Males $(n)$ & 7 & 10 & 14 \\
Females $(n)$ & 23 & 20 & 16 \\
Age (years \pm standard deviation) & $52.2 \pm 14.1$ & $48.9 \pm 15.9$ & $50.3 \pm 17.4$ \\
Caucasian (n) & 25 & 27 & 25 \\
African American (n) & 3 & 0 & 0 \\
\hline
\end{tabular}

Among the samples collected by the Alpha-1 Foundation, plasma levels of A1AT for MZ and ZZ individuals were approximated as $60 \%$ and $20 \%$ of those for MM individuals respectively (Figure 1A). This concentration of A1AT approximates those serum values reported in other study populations in which $\mathrm{ZZ}$ individual demonstrate levels $15 \%$ of MM subjects. ${ }^{19}$ There were significant differences in plasma ferritin concentrations between MM, MZ, and ZZ cohorts (Figure 1B). Those with the ZZ genotype showed greater ferritin values relative to both $\mathrm{MM}$ and $\mathrm{MZ}$ genotypes while there were no differences between MM and MZ (Figure $1 \mathrm{~B} ; \mathrm{F}=5.54 ; P=0.02$ ). When separate analyses of variance were conducted for males and females, the ferritin concentration in the $\mathrm{ZZ}$ cohort was greater than both MM and $\mathrm{MZ}$ for males while only greater than MM subjects for females. Plasma transferrin for MM, MZ, and ZZ cohorts showed no significant differences between them regardless of whether all were included in the analysis or sex-specific values were considered (Figure $1 \mathrm{C} ; \mathrm{F}=2.97 ; P=0.09$ ).

Linear regression analysis revealed a significant (negative) relationship between plasma concentrations of A1AT and ferritin (Figure 2A; $r=0.26 ; P=0.01$ ). Linear regression between A1AT and transferrin levels was not significant (Figure 2B; $\mathrm{r}=0.18 ; P=0.09$ ). The linear regression between ferritin and transferrin was significant (negative) (Figure 2C; $\mathrm{r}=0.39 ; P<0.01)$.

Plasma CRP concentrations were not significantly different between MM, MZ, and ZZ individuals (Figure 3A). Linear regression analysis did not show a significant
A

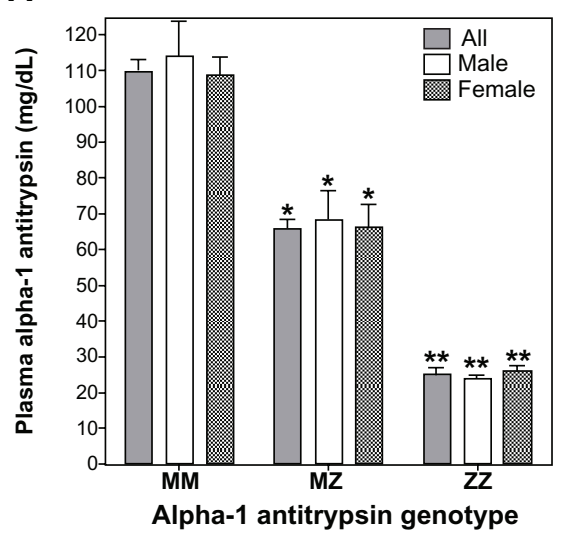

B

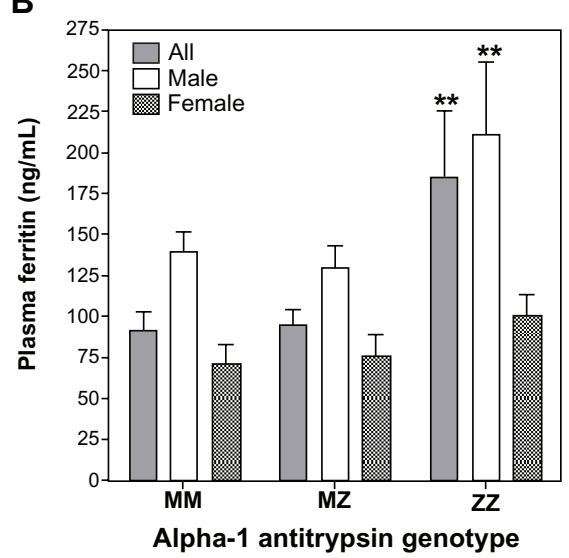

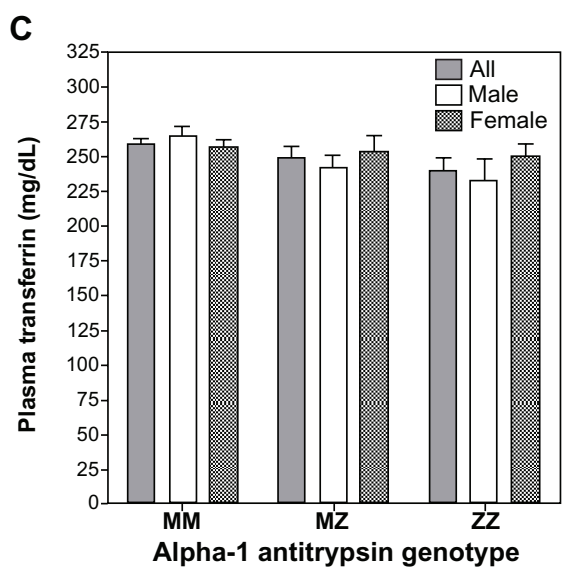

Figure I Concentrations of AIAT, ferritin, and transferrin among MM, MZ, and ZZ cohorts. Relative to the MM genotype, significant decrements in plasma AIAT concentrations were observed in both $M Z$ and $Z Z$ subjects (A). Relative to $M M$ subjects, plasma ferritin levels were significantly increased only in the ZZ cohort (B). Transferrin did not demonstrate differences between the three genotypes (C).

Notes: *Significant difference relative to the comparable sex-specific group of MM; **significant difference relative to the comparable sex-specific groups of MM and MZ. Abbreviation: AIAT, $\alpha-I$ antitrypsin. 
A

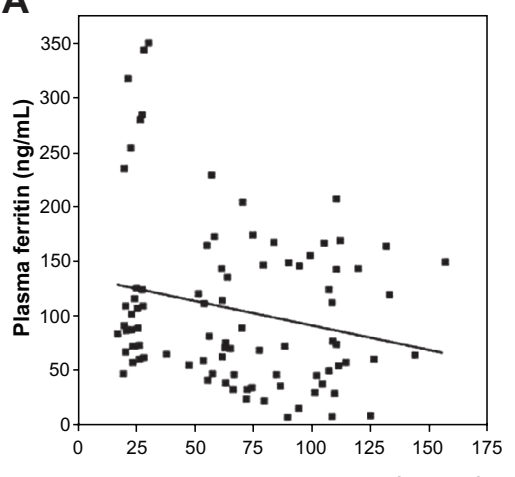

Plasma alpha-1 antitrypsin (mg/dL)

C

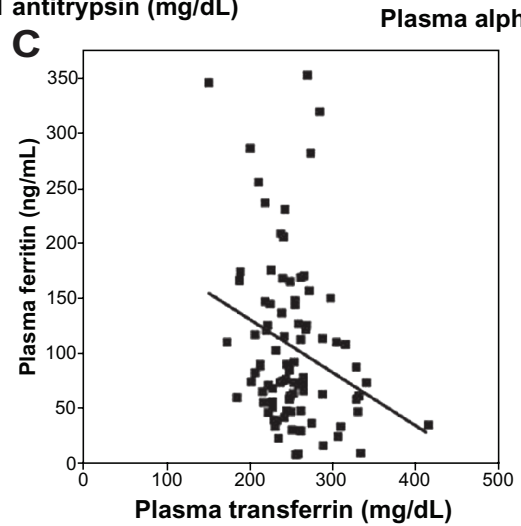

B

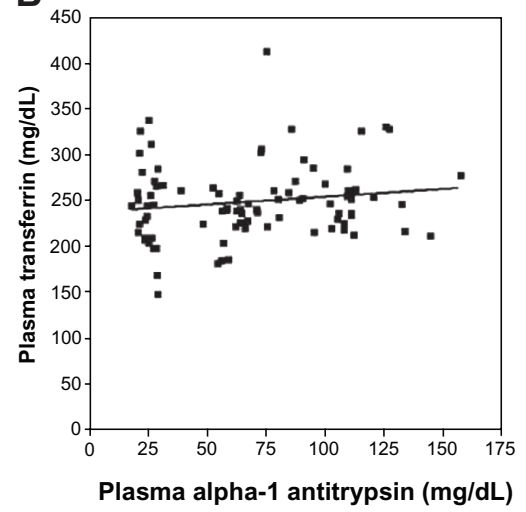

Figure 2 Linear correlations between plasma concentrations of AIAT, ferritin, and transferrin. The correlation between AIAT and ferritin concentrations (A) reached significance while that between AIAT and transferrin (B) did not. The relationship between plasma ferritin and transferrin was negative and significant (C).

Abbreviation: AIAT, $\alpha-I$ antitrypsin.

association between CRP and A1AT (Figure 3B; $r=0.10$; $P=0.36$ ). Regarding the relationships between CRP and indices of iron homeostasis, there was no significant association with either ferritin $(\mathrm{r}=0.17 ; P=0.11)$ or transferrin $(\mathrm{r}=0.20 ; P=0.06)$.

Plasma metal concentrations were significantly different between $\mathrm{MM}$ and $\mathrm{ZZ}$ cohorts for aluminum $(\mathrm{F}=3.10$;
$P=0.05)$ and iron $(\mathrm{F}=3.37 ; P=0.04)$ (Figure $4 \mathrm{~A})$. Zinc also appeared to increase in the $\mathrm{ZZ}$ cohort, but this did not reach significance $(\mathrm{F}=0.49 ; P=0.61)$. Aluminum and iron were elevated in those individuals with the $\mathrm{ZZ}$ genotype relative to the MM genotype; disparities between MM and MZ were not significant. In contrast, copper levels among those with both $\mathrm{MZ}$ and $\mathrm{ZZ}$ genotypes were significantly lower

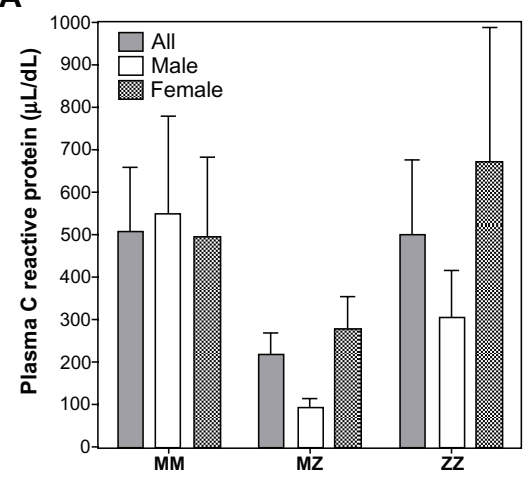

Alpha-1 antitrypsin genotype

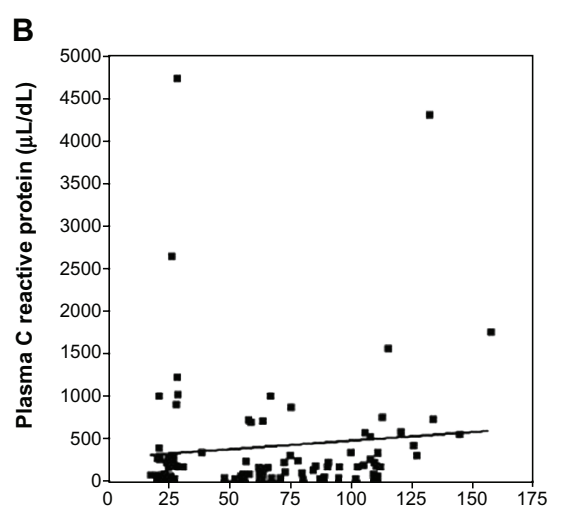

Plasma alpha-1 antitrypsin (mg/dL)

Figure 3 C-reactive protein (CRP) levels in MM, MZ, and ZZ individuals and its correlation with AIAT concentration. There were no significant differences in CRP among the MM, MZ, and ZZ genotypes (A). Similarly, there was no significant correlation between plasma AIAT and CRP concentrations (B).

Abbreviation: AIAT, $\alpha-I$ antitrypsin. 
A

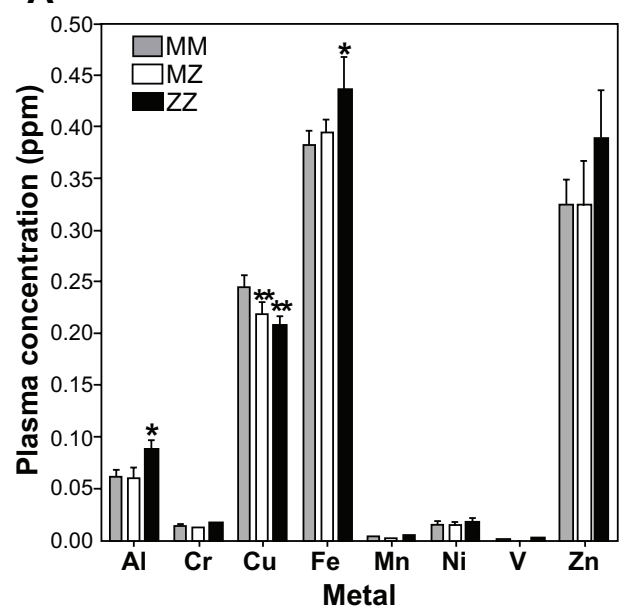

B

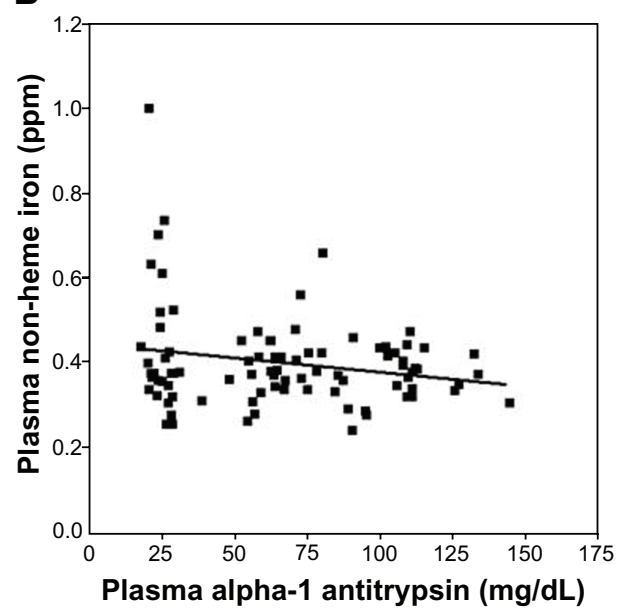

Figure 4 Plasma metal concentrations among MM, MZ, and ZZ cohorts. Aluminum and iron concentrations were observed to increase in ZZ individuals relative to those with $M M$ and $M Z$ genotype (A). In contrast, copper levels decreased in both $M Z$ and $Z Z$ cohorts (A). Only the correlation between AIAT and iron concentration was significant (B). Notes: *Significantly increased relative to the comparable sex-specific group of MM; **significantly decreased relative to the comparable sex-specific group of MM. Abbreviation: AIAT, $\alpha-I$ antitrypsin.

relative to the $\mathrm{MM}$ cohort $(\mathrm{F}=4.33 ; P=0.02)$ (Figure 4A). Correlations of plasma metal concentration with levels of A1AT were significant only for iron (Figure 3B; $r=0.21$; $P=0.05)$.

\section{Discussion}

Ferritin is considered the best available index to measure total body stores of iron. ${ }^{20-22}$ Significant differences in plasma ferritin concentrations between MM and ZZ individuals support an impact of A1AT deficiency on iron homeostasis in humans. Similarly, plasma iron levels were increased in the ZZ genotype. While the MZ genotype decreased A1AT levels, it did not influence ferritin and iron concentrations; this may reflect either a true lack of effect of A1AT genotype on iron homeostasis or the sample number may have been insufficient to demonstrate a difference. The significant correlations between both plasma levels of ferritin and iron with A1 AT also suggest a participation of this anti-protease in iron homeostasis. A relationship between A1AT and ferritin can possibly be predicted since both would increase with inflammation. However, CRP levels were not significantly different between genotypes (MM, MZ, and ZZ) and there was no significant relationship between CRP and ferritin suggesting the increase in ferritin levels among ZZ individuals was not the result of disparities in inflammatory status. In addition, while both A1AT and ferritin are positive acute phase reactants, the relationship between them in our study cohort was an inverse one; that is, as A1AT decreased, ferritin increased. It is not possible to argue that inflammation is responsible for an increase in one index while the other is decreased.
This investigation does not address the molecular basis for a disruption in iron homeostasis in patients with A1AT deficiency. Proteases are employed as a third pathway of iron acquisition by microbials (in addition to siderophores and ferrireductases). ${ }^{23,24}$ These proteins have a capacity to cleave iron-transport and -storage proteins thus allowing utilization of the metal by the microbe. ${ }^{25-27}$ Reflecting potential interactions between metal availability and proteases, increased iron concentrations can impact expression and/or activity of collagenase, elastase, alkaline proteinase, and metalloproteases. ${ }^{9,10,12,28,29}$ In addition, in vitro exposure to the protease inhibitor A1AT alters iron homeostasis in eukaryotic cells. ${ }^{30-34}$ This serpin, which primarily inhibits neutrophil elastase, can elevate intracellular ferritin concentrations in cultured cells. In vivo exposure to protease disrupted iron homeostasis in an animal model. ${ }^{17}$ Finally, among patients with A1AT deficiency, iron homeostasis is disrupted. ${ }^{16,35,36}$ Accordingly, one mechanism through which A1AT deficiency can affect a disruption in iron homeostasis is by allowing an unrestricted activity of specific proteases which would result in increased iron availability. This will lead to elevated tissue concentrations of iron especially in the liver and spleen, which are major cites of storage. Reflecting this, blood ferritin will be increased among individuals with A1AT deficiency.

This disruption in iron homeostasis associated with A1AT deficiency can assist in understanding the clinical presentation of such patients. Clinical manifestations of A1AT deficiency most frequently include liver and lung disease. Liver tissue is one of the major sites for iron storage. With a lack of A1AT, there will be an accumulation of 
iron with subsequent elevations in liver concentrations. Elevated liver iron is associated with hepatitis, cirrhosis, and hepatocarcinoma, which are the manifestations of disease in A1AT deficiency among ZZ individuals. Inhaled exposures (eg, particles) precipitate a biological effect in the lung by disrupting the normal iron homeostasis and increasing the availability of host iron. ${ }^{37}$ Subsequently, particle exposure in A1AT deficient individuals is predicted to be associated with a higher incidence of disease (eg, chronic obstructive pulmonary disease among smokers and those exposed to elevated particle levels). ${ }^{38-40}$

We conclude that A1AT deficiency is associated with evidence of a disruption in iron homeostasis in $\mathrm{ZZ}$ individuals with plasma ferritin and iron concentrations being elevated. Such a disruption in iron homeostasis can contribute to understanding the clinical presentation of A1AT deficiency.

\section{Acknowledgments}

We thank the Alpha-1 Foundation for allowing access to archived plasma samples.

\section{Disclosure}

Bernard Fischer was supported in part by an Alpha-1 Foundation research grant. The other authors have no conflict of interests to declare.

\section{References}

1. Blanco I, Lara B, de Serres F. Efficacy of alpha1-antitrypsin augmentation therapy in conditions other than pulmonary emphysema. Orphanet J Rare Dis. 2011;6:14.

2. Lomas DA. The selective advantage of alpha1-antitrypsin deficiency. Am J Respir Crit Care Med. 2006;173(10):1072-1077.

3. Tuder RM, Janciauskiene SM, Petrache I. Lung disease associated with alphal-antitrypsin deficiency. Proc Am Thorac Soc. 2010;7(6):381-386.

4. Stoller JK, Aboussouan LS. Alpha1-antitrypsin deficiency. Lancet. 2005;365(9478):2225-2236.

5. Luisetti M, Seersholm N. Alpha1-antitrypsin deficiency. 1: epidemiology of alpha1-antitrypsin deficiency. Thorax. 2004;59(2):164-169.

6. Marx JJ. Iron and infection: competition between host and microbes for a precious element. Best Pract Res Clin Haematol. 2002;15(2):411-426.

7. Britigan BE, Hayek MB, Doebbeling BN, Fick RB Jr. Transferrin and lactoferrin undergo proteolytic cleavage in the Pseudomonas aeruginosa-infected lungs of patients with cystic fibrosis. Infect Immun. 1993;61(12):5049-5055.

8. Miller RA, Britigan BE. Protease-cleaved iron-transferrin augments oxidant-mediated endothelial cell injury via hydroxyl radical formation. J Clin Invest. 1995;95(6):2491-2500.

9. Gardi C, Arezzini B, Fortino V, Comporti M. Effect of free iron on collagen synthesis, cell proliferation and MMP-2 expression in rat hepatic stellate cells. Biochem Pharmacol. 2002;64(7):1139-1145.

10. Shigematsu T, Fukushima J, Oyama M, Tsuda M, Kawamoto S, Okuda $\mathrm{K}$. Iron-mediated regulation of alkaline proteinase production in Pseudomonas aeruginosa. Microbiol Immunol. 2001;45(8):579-590.
11. Brumlik MJ, Storey DG. Zinc and iron regulate translation of the gene encoding Pseudomonas aeruginosa elastase. Mol Microbiol. 1992;6(3):337-344.

12. Okazaki I, Brinckerhoff CE, Sinclair JF, Sinclair PR, Bonkowsky HL, Harris ED Jr. Iron increases collagenase production by rabbit synovial fibroblasts. J Lab Clin Med. 1981;97(3):396-402.

13. Stites SW, Plautz MW, Bailey K, O’Brien-Ladner AR, Wesselius LJ. Increased concentrations of iron and isoferritins in the lower respiratory tract of patients with stable cystic fibrosis. Am J Respir Crit Care Med. 1999;160(3):796-801.

14. Reid DW, Lam QT, Schneider H, Walters EH. Airway iron and iron-regulatory cytokines in cystic fibrosis. Eur Respir J. 2004;24(2):286-291.

15. Lucey EC, Stone PJ, Christensen TG, Breuer R, Snider GL. An 18-month study of the effects on hamster lungs of intratracheally administered human neutrophil elastase. Exp Lung Res. 1988;14(5):671-686.

16. Rabinovitz M, Gavaler JS, Kelly RH, Van Thiel DH. Association between heterozygous alpha 1-antitrypsin deficiency and genetic hemochromatosis. Hepatology. 1992;16(1):145-148.

17. Fischer BM, Domowicz DA, Zheng S, et al. Neutrophil elastase increases airway epithelial nonheme iron levels. Clin Transl Sci. 2009;2(5):333-339.

18. McNabb JC, Cappa JA, Ross JW. Disorders of iron metabolism associated with protease inhibitor therapy. Clin Infect Dis. 2001;33(3):413-414.

19. Alpha 1-antitrypsin deficiency: memorandum from a WHO meeting. Bull World Health Organ. 1997;75(5):397-415.

20. Jacobs EM, Hendriks JC, van Deursen CT, et al. Severity of iron overload of proband determines serum ferritin levels in families with HFE-related hemochromatosis: the HEmochromatosis FAmily Study. J Hepatol. 2009;50(1):174-183.

21. Herbert V, Jayatilleke E, Shaw S, et al. Serum ferritin iron, a new test, measures human body iron stores unconfounded by inflammation. Stem Cells. 1997;15(4):291-296.

22. Powell LW, Halliday JW, Cowlishaw JL. Relationship between serum ferritin and total body iron stores in idiopathic haemochromatosis. Gut. 1978;19(6):538-542.

23. Rauscher L, Expert D, Matzanke BF, Trautwein AX. Chrysobactindependent iron acquisition in Erwinia chrysanthemi. Functional study of a homolog of the Escherichia coli ferric enterobactin esterase. J Biol Chem. 2002;277(4):2385-2395.

24. Brochu V, Grenier D, Nakayama K, Mayrand D. Acquisition of iron from human transferrin by Porphyromonas gingivalis: a role for Arg- and Lys-gingipain activities. Oral Microbiol Immunol. 2001;16(2):79-87.

25. Miller RA, Rasmussen GT, Cox CD, Britigan BE. Protease cleavage of iron-transferrin augments pyocyanin-mediated endothelial cell injury via promotion of hydroxyl radical formation. Infect Immun. 1996;64(1):182-188.

26. Wolz C, Hohloch $\mathrm{K}$, Ocaktan A, et al. Iron release from transferrin by pyoverdin and elastase from Pseudomonas aeruginosa. Infect Immun. 1994;62(9):4021-4027.

27. Brines RD, Brock JH. The effect of trypsin and chymotrypsin on the in vitro antimicrobial and iron-binding properties of lactoferrin in human milk and bovine colostrum. Unusual resistance of human apolactoferrin to proteolytic digestion. Biochim Biophys Acta. 1983;759(3):229-235.

28. Santos JA, Gonzalez CJ, Lopez TM, Otero A, Garcia-Lopez ML. Hemolytic and elastolytic activities influenced by iron in Plesiomonas shigelloides. J Food Prot. 1999;62(12):1475-1477.

29. Sokol PA, Cox CD, Iglewski BH. Pseudomonas aeruginosa mutants altered in their sensitivity to the effect of iron on toxin A or elastase yields. J Bacteriol. 1982;151(2):783-787.

30. Graziadei I, Kahler CM, Wiedermann CJ, Vogel W. The acute-phase protein alpha 1-antitrypsin inhibits transferrin-receptor binding and proliferation of human skin fibroblasts. Biochim Biophys Acta. 1998;1401(2):170-176.

31. Weiss G, Graziadel I, Urbanek M, Grunewald K, Vogel W. Divergent effects of alpha 1-antitrypsin on the regulation of iron metabolism in human erythroleukaemic (K562) and myelomonocytic (THP-1) cells. Biochem J. 1996;319 (Pt 3):897-902. 
32. Graziadei I, Weiss G, Bohm A, Werner-Felmayer G, Vogel W. Unidirectional upregulation of the synthesis of the major iron proteins, transferrin-receptor and ferritin, in HepG2 cells by the acute-phase protein alpha1-antitrypsin. J Hepatol. 1997;27(4):716-725.

33. Graziadei I, Kaserbacher R, Braunsteiner H, Vogel W. The hepatic acute-phase proteins alpha 1-antitrypsin and alpha 2-macroglobulin inhibit binding of transferrin to its receptor. Biochem J. 1993;290(Pt 1): 109-113.

34. Graziadei I, Weiss G, Egger C, Niederwieser D, Patsch JR, Vogel W. Modulation of iron metabolism in monocytic THP-1 cells and cultured human monocytes by the acute-phase protein alpha1-antitrypsin. Exp Hematol. 1998;26(11):1053-1060.

35. Kaserbacher R, Propst T, Propst A, Graziadei I, Judmaier G, Vogel W. Association between heterozygous alpha 1-antitrypsin deficiency and genetic hemochromatosis. Hepatology. 1993;18(3):707-708.
36. Brunt EM, Tavill AS, Bacon BR. A 49-year-old man with alpha 1-antitrypsin deficiency and abnormal iron study results. Semin Liver Dis. 1996;16(1):97-101.

37. Ghio AJ. Disruption of iron homeostasis and lung disease. Biochim Biophys Acta. 2009;1790(7):731-739.

38. Mayer AS, Stoller JK, Bucher Bartelson B, James Ruttenber A, Sandhaus RA, Newman LS. Occupational exposure risks in individuals with PI*Z alpha(1)-antitrypsin deficiency. Am J Respir Crit Care Med. 2000;162(2 Pt 1):553-558.

39. Banauch GI, Brantly M, Izbicki G, et al. Accelerated spirometric decline in New York City firefighters with alpha-antitrypsin deficiency. Chest. 2010;138(5):1116-1124.

40. Wood AM, Harrison RM, Semple S, Ayres JG, Stockley RA. Outdoor air pollution is associated with disease severity in alpha1-antitrypsin deficiency. Eur Respir J. 2009;34(2):346-353.

\section{Publish your work in this journal}

The International Journal of COPD is an international, peer-reviewed journal of therapeutics and pharmacology focusing on concise rapid reporting of clinical studies and reviews in COPD. Special focus is given to the pathophysiological processes underlying the disease, intervention programs, patient focused education, and self management protocols.

\section{Dovepress}

This journal is indexed on PubMed Central, MedLine and CAS. The manuscript management system is completely online and includes a very quick and fair peer-review system, which is all easy to use. Visit http://www.dovepress.com/testimonials.php to read real quotes from published authors. 